\title{
Itinerários terapêuticos de sujeitos com problemáticas decorrentes do uso prejudicial de álcool ${ }^{*}$
}

Ana Lucia Marinho Marques ${ }^{1}$

Elisabete Ferreira Mângia²

MARQUES, A.L.M.; MÂNGIA, E.F. Therapeutic Itineraries of individuals with problems consequent to harmful use of alcohol. Interface (Botucatu), v.17, n.45, p.433-44,

abr./jun. 2013.

This study aimed to ascertain the therapeutic itineraries of individuals with problems consequent to harmful use of alcohol, at a psychosocial care center for users of alcohol and other substances. It was based on qualitative methods and took an ethnomethodological perspective. It used the methodological procedures of bibliographical review, document research, semi-structured interviews, focus groups, participant observation and field diaries. The therapeutic itineraries were configured from the experience constructed, which attributed meanings to experiences relating to alcohol use and the need for help. The importance of social networks in which people share meanings and support was highlighted. The course of this study showed the importance of ascertaining individuals' knowledge and practices, in proposing care actions with a commitment towards production of health and life.

Keywords: Therapeutic itineraries. Substance-related disorders. Alcoholism. Community mental health services.
Este estudo visou conhecer itinerários terapêuticos de sujeitos com problemáticas decorrentes do uso prejudicial de álcool em um Centro de Atenção Psicossocial para usuários de álcool e outras drogas - CAPSad. A pesquisa, de caráter qualitativo, adotou a perspectiva etnometodológica e empregou os seguintes procedimentos metodológicos: revisão bibliográfica, pesquisa documental, entrevistas semiestruturadas, grupo focal, observação participante e diário de campo. Os itinerários terapêuticos se configuram a partir da experiência construída, que dota de significados as vivências relacionadas ao uso de álcool e a necessidade de ajuda. Destaca-se a importância das redes sociorrelacionais, no contexto das quais são compartilhados sentidos, significados e suporte. O percurso da pesquisa mostrou a importância de se conhecerem os saberes e práticas dos sujeitos na proposição de práticas de cuidado comprometidas com produção de saúde e de vida.

Palavras-chave: Itinerários terapêuticos. Transtornos relacionados ao uso de substâncias. Alcoolismo. Serviços comunitários de saúde mental.

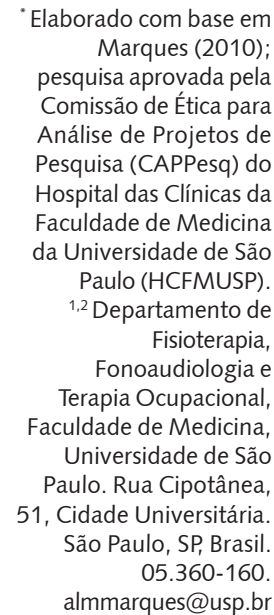


ITINERÁRIOS TERAPÊUTICOS ...

\section{Introdução}

De acordo com dados da Organização Mundial da Saúde, cerca de dois bilhões de pessoas em todo o mundo consomem bebidas alcoólicas - o que corresponde a, aproximadamente, $40 \%$ da população mundial acima de 15 anos - e cerca de 76,3 milhões apresentam problemáticas decorrentes do uso dessa substância. Em muitos países, é alta a carga global relacionada ao consumo de álcool, tanto em termos de morbidade quanto de mortalidade. O consumo de álcool pode trazer consequências diversas, e está relacionado a mais de sessenta tipos de doenças ou lesões, além de episódios de violência, homicídios e acidentes; está associado a 3,2\% de todas as mortes no mundo (sendo, aproximadamente, $6 \%$ de todas as mortes entre homens, e $1 \%$ entre as mulheres) e $4 \%$ do total de anos de vida comprometidos por alguma incapacidade (Anthony, 2009; World Health Organization - WHO, 2004, 2002).

No Brasil, pesquisas consideram que $12 \%$ da população apresentam problemas decorrentes do uso de álcool, associados ao uso nocivo e à dependência. Para o campo da saúde pública, este índice é especialmente significativo, pois uma parte substancial dessas pessoas necessita de alguma forma de tratamento ou apresenta algum quadro clínico que requer ações do sistema de saúde (Laranjeira et al., 2007).

Nos últimos anos, o Ministério da Saúde tem formulado diretrizes e construído propostas de atenção para abordar essa problemática, no contexto do Sistema Único de Saúde, que consideram: a relevância epidemiológica do problema; a necessidade de incluir os usuários/dependentes de álcool e outras drogas em uma rede ampliada de cuidados; a consciência da urgência de adaptar-se a legislação vigente sobre álcool e outras drogas aos objetivos da saúde pública e de acordo com uma perspectiva que não seja baseada na punição; a compreensão das estratégias de redução de danos como alternativas eficazes no tratamento e na prevenção (Brasil, 2007; 2003).

Tal projeto assistencial respeita diretrizes aceitas internacionalmente e situa-se no contexto da construção de serviços de saúde baseados na comunidade que buscam evitar a hospitalização e atender os sujeitos em seus territórios de forma integral, e não focalizada estritamente na doença (OMS, 2001).

Nesse contexto, ganham destaque os Centros de Atenção Psicossocial para atendimento de indivíduos com transtornos causados pelo uso prejudicial e/ou dependência de álcool e outras drogas (CAPSad). Instituídos a partir da Portaria n 336/GM (Brasil, 2003; 2002), esses serviços devem oferecer atenção diária e obedecer à lógica de oferta de cuidados baseados na atenção integral, com práticas terapêuticas, preventivas, de promoção de saúde, educativas e de reabilitação psicossocial. Também devem responsabilizar-se pela articulação da rede de atenção integral aos usuários de álcool e outras drogas, composta por serviços situados nos diversos níveis assistenciais (Brasil, 2004a; 2004b).

O acompanhamento contínuo e cotidiano favorece a ampliação de processos de trocas e de oportunidades de inclusão social. Os CAPSad são espaços privilegiados para a construção de projetos terapêuticos cuidadores, centrados nas reais e singulares necessidades, desejos e potencialidades dos sujeitos, e na corresponsabilidade entre usuários, técnicos e outros atores envolvidos (Brasil, 2004b; Franco, Magalhães Junior, 2004; Saraceno, 1998).

\section{A construção de itinerários terapêuticos}

Os indivíduos desenvolvem maneiras peculiares de estarem no mundo e de vivenciarem seus sofrimentos, alegrias, frustrações, vitórias e inseguranças. Da mesma maneira, estabelecem relações com suas experiências de enfermidade e desenvolvem trajetórias para resolver seus problemas de saúde que são singulares e sustentadas em determinado campo relacional (Alves, 2006; Alves, Souza, 1999).

Assim como os demais processos de decisão que ocorrem cotidianamente, os processos de escolha por determinada prática terapêutica são criados e compartilhados no contexto das redes sociorrelacionais e se constituem a partir do sentido e dos significados que os indivíduos atribuem a essas vivências. Diante da situação de enfermidade, os indivíduos tendem a iniciar uma trajetória em busca de respostas para seus problemas. Tal trajetória ou "itinerário terapêutico" pode ser definida como "um conjunto de 
planos, estratégias e projetos voltados para um objeto preconcebido: o tratamento da aflição" (Alves, Souza, 1999, p.133).

Os estudos sobre itinerários terapêuticos objetivam conhecer os processos pelos quais os indivíduos "escolhem, avaliam e aderem (ou não) a determinados tipos de tratamento" (Alves, Souza, 1999, p.125). Consideram que esses processos são ações humanas, singulares e contextualizadas, que mesclam múltiplas formas de conhecimento e de práticas, de maneira que não é possível formular uma teoria explicativa única para compreender tais processos (Alves, Souza, 1999).

Por meio de narrativas, pode-se perceber que os indivíduos se engajam em determinado sistema terapêutico ou recorrem, simultaneamente, a vários tratamentos, orientados por experiências anteriores e pelo conhecimento produzido na interação com as outras pessoas (Alves, Souza, 1999; Alves, 1993).

Embora os indivíduos atuem e se desenvolvam em contextos socioculturais específicos, suas ações não são fixadas pelas estruturas sociais que, ao contrário, permitem a criação de modos singulares de existência. Sem perder de vista o contorno oferecido pelos macroprocessos históricos e socioculturais, os estudos sobre itinerários terapêuticos buscam conhecer: os microfundamentos da experiência de enfermidade e de busca de tratamento, as ações que os sujeitos realizam cotidianamente e os procedimentos utilizados, as trajetórias e projetos singularmente elaborados e intersubjetivamente legitimados (Alves, Souza, 1999).

Este estudo visou conhecer os itinerários terapêuticos de sujeitos com problemáticas decorrentes do uso prejudicial de álcool, em um centro de atenção psicossocial para usuários de álcool e outras drogas (CAPSad). Especificamente, buscou: identificar aspectos que levam os sujeitos a reconhecerem o uso de álcool como um problema; descrever suas estratégias de busca de respostas para seu problema, e conhecer suas opiniões sobre as experiências de tratamento e cuidado.

\section{Procedimentos metodológicos}

Neste estudo, a construção do trabalho de campo buscou inspiração na perspectiva etnometodológica e caracterizou-se pela pesquisa dos procedimentos que os sujeitos utilizam para construir, manter e transformar o mundo em que vivem. A compreensão de suas experiências se deu a partir dos objetos, situações e símbolos que os cercam, articuladas, compartilhadas e sustentadas em seus contextos relacionais (Angrosino, 2009; Denzin, Lincoln, 2006; Coulon, 1995).

A inspiração etnometodológica propiciou a formulação da postura utilizada no desenvolvimento do trabalho de campo, realizado no CAPSad "Travessia", situado no município de Santana de Parnaíba/SP, no período de janeiro a março de 2009. Utilizou-se de técnicas e métodos do campo da pesquisa qualitativa, e empreenderam-se os seguintes procedimentos metodológicos: revisão bibliográfica, pesquisa documental, entrevistas semiestruturadas, grupo focal, observação participante e construção de um diário de campo.

É importante considerar que os questionamentos e reflexões que impulsionaram a realização da pesquisa são fruto de um processo anterior de imersão no campo, pois a pesquisadora já fazia parte da equipe do serviço havia dois anos e meio, desempenhando atividades como terapeuta ocupacional. Tal situação exigiu o exercício constante de deslocamento do lugar de terapeuta para o de pesquisadora, discutido e sustentado pelo grupo de profissionais e de usuários participantes.

Primeiramente, foram discutidos, com a diretoria técnica-administrativa do serviço, os objetivos da pesquisa e os procedimentos metodológicos que se pretendia utilizar. Em seguida, em uma reunião técnica, foi possível discutir e avaliar o projeto com a equipe, que contribuiu com sugestões, alterações e na elaboração do cronograma de realização. Na sequência, foi realizado contato com os usuários que foram eleitos pela equipe para participarem da pesquisa. Com cada um deles, foi agendado um encontro para fazer o convite à participação e apresentar, detalhadamente, os objetivos e procedimentos da pesquisa, além de prestar esclarecimentos sobre sua participação e solicitar sugestões. Nesse momento, também, foi apresentado o Termo de Consentimento Livre e Esclarecido, que foi assinado por todos. 
ITINERÁRIOS TERAPÊUTICOS ...

As relações anteriormente estabelecidas contribuíram para que se criasse um clima confortável na realização dos grupos e das entrevistas, em que os participantes conseguiram expor livremente suas ideias. Além disso, foi possível realizar o processo de observação participante sem que a presença da pesquisadora fosse questionada, como pode acontecer quando o observador é externo ao grupo. Criaram-se, espontaneamente, alguns momentos de interação informal com os participantes, em que foi possível colher informações que não apareceram nas entrevistas e que, também, possibilitavam rever algumas estratégias da pesquisa.

Participaram da pesquisa oito usuários do serviço, selecionados pela equipe técnica a partir de um processo de discussão, e de acordo com os seguintes critérios definidos pelo pesquisador: serem usuários de álcool, estarem em atendimento nos três meses que antecederam o início da coleta de dados, de ambos os sexos, com idade entre trinta e sessenta anos. Para realizar a escolha, a equipe foi orientada acerca de que o objetivo era o de constituir um grupo heterogêneo e representativo do serviço, que pudesse contribuir na captação da maior variedade de opiniões e no conhecimento de diferentes histórias de vida, distintos processos de busca de auxílio e tipos de vínculos estabelecidos com o serviço.

Foram realizados dois encontros de grupo focal, com duração de 1 h30min cada, e uma entrevista individual para a qual todos os participantes foram convidados, com a utilização de um roteiro que combinou questões abertas e fechadas. Tanto as discussões em grupo quanto as entrevistas foram gravadas e, posteriormente, transcritas pelo próprio pesquisador.

O processo de observação participante buscou conhecer a forma como os usuários participantes da pesquisa utilizam o serviço, priorizando a observação dos momentos informais de contato destes com outros usuários e com os profissionais. Nesse processo, também criaram-se, espontaneamente, momentos de interação informal com os participantes, em que foi possível colher informações que não apareceram nas entrevistas e que também possibilitavam rever algumas estratégias da pesquisa.

No diário de campo, foram descritas situações consideradas importantes para o estudo, o processo de realização das entrevistas e discussões em grupo, bem como as impressões e reflexões elaboradas pelo pesquisador durante a realização das observações. O uso de estratégias mistas possibilitou comparar discursos e práticas dos sujeitos, maior aproximação com a experiência estudada e a apreensão ampla do fenômeno em questão (Denzin, Lincoln, 2006; Coulon, 1995).

Todos os participantes aceitaram e confirmaram sua participação por meio de assinatura dos Termos de Consentimento Livre e Esclarecido. A pesquisa obteve consentimento da Diretoria TécnicoAdministrativa do CAPSad "Travessia". De acordo com as normas para pesquisa prescritas pelo Conselho Nacional de Saúde, o projeto e os Termos de Consentimento foram apresentados para apreciação da Comissão de Ética para Análise de Projetos de Pesquisa (CAPPesq) do Hospital das Clínicas da Faculdade de Medicina da Universidade de São Paulo (HCFMUSP), e aprovados.

Para o processo de análise dos dados obtidos, optou-se pela combinação das estratégias propostas pelas técnicas de análise de enunciação e análise temática. Tal escolha se deu tendo como pressuposto a concepção de que os discursos são elaborados em processos dinâmicos e expressam: opiniões, contradições, reações afetivas e incertezas existentes no momento de sua produção e em dado contexto de realização. Desta forma, foram analisados tanto os conteúdos expressos pelos depoentes quanto o contexto e o processo de produção da narrativa (Silvermann, 2009; Minayo, 1993).

Ao final da coleta de dados, reuniu-se todo o material produzido, e os temas identificados como mais relevantes foram agregados em categorias elaboradas a partir dos objetivos do estudo, e relacionadas aos referenciais teóricos assumidos (Gibbs, 2009; Minayo, 1993). Tais categorias serão explicitadas na apresentação dos resultados.

\section{Caracterização do campo da pesquisa}

As estratégias de cuidado com a saúde são construídas e compartilhadas intersubjetivamente, e as especificidades de cada contexto onde são realizadas podem ser agentes disparadores de determinadas escolhas, especialmente no que tange à oferta e acesso aos serviços e recursos existentes. Dessa forma, para a compreensão dos itinerários terapêuticos dos sujeitos, é importante observar o contexto onde as ações empreendidas se realizam (Gerhardt, 2006; Alves, Souza, 1999). 
Como já apontado, o trabalho de campo foi realizado no CAPSad "Travessia", localizado em Santana de Parnaíba/SP. O município tem, de acordo com estimativas do IBGE, população de 110.730 habitantes e sustenta o $23^{\circ}$ melhor Índice de Desenvolvimento Humano (IDH-M) do País, sendo o $2^{\circ}$ melhor da Região Metropolitana de São Paulo. Todavia, de acordo com o índice de Gini, o município ocupa $1^{\circ}$ lugar no ranking de desigualdade do Estado de São Paulo e $35^{\circ}$ lugar entre os municípios de todo o País. Em 2000, de acordo com o Censo, os 10\% mais ricos do município ganhavam 66 vezes mais que os 40\% mais pobres (Instituto Brasileiro de Geografia e Estatística - IBGE, 2008; Santana de Parnaíba, 2006; Programa das Nações Unidas para o Desenvolvimento - PNUD, 2003).

A análise do Índice Paulista de Vulnerabilidade Social (IPVS) também mostra dados importantes para a caracterização do município. Entre outros aspectos, chama a atenção o fato de que $70 \%$ da população apresentam algum grau de vulnerabilidade. Apesar de possuir bons índices de desenvolvimento, trata-se de um município no qual convivem disparidades populacionais e regionais, com áreas que demandam maior atenção na formulação e execução das políticas públicas municipais (Fundação Sistema Estadual de Análise de Dados- SEADE, 2009).

Com relação à atenção comunitária em saúde mental, o município de Santana de Parnaíba dispõe de uma rede de serviços que, no momento de realização do trabalho de campo, era composta por: um CAPS II, um CAPSad (Álcool e Drogas), um CAPS Infantil, um Ambulatório de Saúde Mental e Adolescência, e equipes básicas de Saúde Mental lotadas em todas as Unidades Básicas de Saúde (UBS) e nas denominadas Unidades de Saúde Avançada (USA).

Desta rede, destacou-se o CAPSad "Travessia", serviço em funcionamento desde dezembro de 2004, e que tem por objetivo ser referência, para o município, na prevenção, tratamento e reabilitação psicossocial dos sujeitos com transtornos decorrentes do uso prejudicial ou dependência de álcool, tabaco e outras drogas.

\section{Participantes do estudo}

O grupo de oito participantes do estudo foi formado por sujeitos com idade entre trinta e sessenta anos, de ambos os sexos (sendo duas mulheres e seis homens), e que apresentavam transtornos decorrentes do uso de álcool. No momento de realização da pesquisa, quatro estavam trabalhando, sendo que nenhum estava inserido no mercado formal de trabalho. A maioria morava com familiares, com exceção de dois participantes, que moravam sozinhos.

Em um primeiro momento, os oito participantes frequentaram o CAPSad intensivamente e essa frequência foi gradativamente diminuída. Dependendo da demanda apresentada, foram estabelecidos projetos terapêuticos diferenciados, com a possibilidade de momentos de intensificação do cuidado ao longo do trajeto. No momento de realização da pesquisa, cada participante utilizava o serviço de forma diferenciada, participando de determinados grupos e oficinas de acordo com suas necessidades e afinidades.

\section{Resultados e discussão}

No processo de análise dos dados colhidos, após a identificação de temas que se configuraram como relevantes, foram estabelecidos os códigos analíticos abaixo apresentados (Gibbs, 2009), alinhados aos objetivos do estudo. Para preservar a identidade dos participantes, eles foram identificados pelas letras de $\mathrm{A}$ a $\mathrm{H}$.

\section{Do uso ocasional à experiência da dependência}

Foi possível observar que, inicialmente, o consumo de bebidas alcoólicas ocorreu por diversos motivos e em diferentes contextos. Para alguns sujeitos, o álcool fez parte do cotidiano familiar, incitado pelos pais ou outros familiares. Também foi associado a situações de lazer e sociabilidade, estimulado por amigos ou, mesmo, pela mídia. 
ITINERÁRIOS TERAPÊUTICOS ...

Outros o associaram a vivências de situações nas quais buscaram alívio para sentimentos de raiva, medo ou tristeza. Neste caso, o consumo de álcool foi compreendido como fonte de prazer, alívio, desinibição e descontração. Com o aumento do uso, ao longo do tempo, foram percebidos os primeiros prejuízos. Apesar de referirem-se à bebida como "a malvada", reconhecem que as consequências negativas do uso não estão ligadas exclusivamente à substância psicoativa em si, mas, sim, à relação que estabeleceram com ela.

"Mas é que a gente não sabe beber, e enquanto não vê o fundo da garrafa, a gente não sossega. [...] A gente não tem esse controle. Então, esse é que é o problema". (C)

A percepção de que se está diante de uma questão a ser enfrentada é marcada pela consciência da perda de controle sobre o uso, a impossibilidade de realizar as atividades cotidianas na ausência do álcool, a insuportabilidade da abstinência, e a dificuldade de interromper o consumo a despeito da percepção do problema e de suas consequências.

No relato dos participantes, notou-se, também, que, gradativamente, houve aumento do tempo utilizado para o consumo da substância, que provocou o abandono de suas atividades produtivas e de lazer e o estreitamento dos laços e espaços de intercâmbios sociais, com a limitação ao convívio com o núcleo familiar e com os chamados "colegas de bar".

"Quando você vê, já tá dependente [...] Você fica viciado e ela se torna uma doença. Fica dependente da bebida e não consegue mais viver sem [...]. É uma de manhã para parar de tremer, é duas pra almoçar, é duas à tarde, é quatro pra jantar... Aí vai. Eu já estava tomando mais de um litro de pinga por dia". (G)

No contexto sociofamiliar, os sujeitos percebem-se submissos e desvalorizados. Relatam perda de poder contratual nas decisões relativas às questões domésticas e de trabalho. Rotulados como "bêbados", são vistos apenas como "um copo de bebida", e invalidados no exercício dos papéis sociais.

“A moral da gente também vai pro lixo. [...] O cara alcoolizado não tem razão de nada. Ele, quieto, já tá errado. [...] Já tá incomodando com o cheiro de álcool [...]. O pessoal ia me procurar não porque eu sou um bom profissional, mas porque eu trabalhava a troco de bebida. "Ah, você dá um maço de cigarro e uma garrafa de pinga pro cara lá e ele faz isso aí legal pra você". E o seu valor, vai pra onde?". (G)

\section{Compreensão e construção de significados}

A compreensão sobre a questão vivenciada contempla aspectos de julgamento moral, ligados às noções de força e virtude individual. Apesar de desencadear diversos problemas de saúde, a dependência é compreendida como fraqueza moral. A falta de limites no consumo é difícil de ser admitida pelos sujeitos, pois parece implicar a afirmação da fragilidade e incapacidade de controlar o próprio corpo. O sofrimento corporal não é, geralmente, percebido e legitimado pelo grupo social, que estabelece julgamentos e atua de forma preconceituosa.

Embora reconheçam a dificuldade em interromper o uso - "o vício é maior que tudo" (C), "é mais forte que a gente" (C) -, identificam o momento no qual tomaram a decisão de parar, e acreditam que isso é o que falta àqueles que ainda não tiveram "coragem" ou "vontade" suficientes para tentar interromper o consumo ou buscar algum tipo de auxílio. Quando comentam sobre algum usuário que "recaiu" ou abandonou o tratamento, avaliam que a "culpa" é do indivíduo, que não teve a vontade ou determinação necessária.

Quando se referem àqueles que já alcançaram a abstinência e a reorganização da vida cotidiana sem o uso de álcool, afirmam a necessidade de estar "em alerta", como se a "força" adquirida pudesse ser facilmente perdida. 
“Uma coisa que eu sempre falo 'Quando a gente pensa que tá forte, que a gente tá fraco'. A gente tem que sempre tomar cuidado". (B)

\section{O processo de busca de auxílio e soluções}

No início, o processo de busca de tratamento e cuidado é constituído por tentativas isoladas e solitárias de interrupção do consumo. Diante da situação de perda de controle, os sujeitos colocam, para si, o desafio de recuperarem a "força" perdida. É só depois de certo tempo e de algumas tentativas, com a vivência de situações que se configuram enquanto "limite" para cada um, que solicitam auxílio para sua rede de relações.

O insucesso das tentativas é atribuído à dificuldade de alcançar e manter a abstinência sem ter suporte ou continência de profissionais especializados ou de grupos religiosos. Afirmam que a maior dificuldade para "parar sozinhos" advém das consequências e desconfortos que caracterizam a síndrome de abstinência alcoólica.

A internação é a resposta mais conhecida e a primeira a ser procurada. Em alguns casos, a procura por tratamento foi postergada por não aceitarem a internação, embora acreditassem ser essa a única possibilidade.

Nas trajetórias descritas, observou-se a passagem por serviços de saúde, em decorrência de algum comprometimento associado ou decorrente do uso crônico de álcool. Foi através da experiência da doença, vivida e corporificada, que a maioria identificou a necessidade de enfrentar a situação. $O$ agravamento do quadro clínico pode levar os sujeitos a situações consideradas "limite", como: cirrose e outras doenças hepáticas alcoólicas, convulsões, alucinose alcoólica e delirium tremens.

No geral, a chegada aos serviços de saúde ocorreu devido aos comprometimentos clínicos severos, e não pela compreensão de que tais serviços poderiam contribuir na resolução da problemática vivenciada. Os sujeitos recorreram, simultaneamente, a outras ofertas de tratamento e ajuda, e chegaram ao CAPSad sem conhecerem sua proposta terapêutica e sem a formulação clara sobre seu próprio problema.

Observou-se que a procura pelo serviço de saúde ocorre no contexto de um processo pouco racionalizado. Nele se destaca a importância das redes sociais, orientando e sustentando os processos de busca de ajuda. Os sujeitos relatam não terem recebido ajuda inicialmente, embora tenha sido observado que o suporte das redes sociofamiliares esteve sempre presente ao longo do processo de reconhecimento do problema e busca de ajuda. Por outro lado, os sujeitos reconhecem a importância e nutrem expectativas positivas sobre o apoio que podem receber de suas redes sociais.

Notou-se que o envolvimento das redes sociais é complexo e dinâmico e alternam-se momentos de fortalecimento, quando se aproximam para oferecer ajuda, e fragilização de vínculos, quando vivem momentos de impotência diante das dificuldades dos sujeitos. Há mobilização para ajudar na interrupção do uso e ajuda na construção do projeto de tratamento, mesmo quando não há o pedido expresso dos sujeitos.

\section{A construção de projetos terapêuticos no CAPSad}

As trajetórias empreendidas na busca de estratégias para o enfrentamento das questões decorrentes do uso prejudicial de álcool são diversas e distintas, sendo também diferenciados os momentos de chegada ao CAPSad. De forma geral, a escolha por este serviço não parece associada a um processo racional e de análise sobre vantagens e desvantagens das ofertas existentes. Os participantes afirmam que o CAPSad foi indicado por alguém da sua rede de relacionamentos e resolveram conhecer o serviço. Para alguns, essa escolha também se deu devido à escassez de ofertas terapêuticas: não conheciam lugares no município que pudessem oferecer algum tipo de suporte ou tentaram recorrer à internação, mas não encontraram vagas disponíveis. Também foi relatada a recorrência simultânea a outros espaços de apoio e outras modalidades de tratamento, como: internação em clínicas ou comunidades terapêuticas, grupos de ajuda mútua (Alcoólicos Anônimos) ou grupos religiosos, por exemplo. 
ITINERÁRIOS TERAPÊUTICOS ...

Também foram observadas situações em que a percepção e o reconhecimento das problemáticas decorrentes do uso de álcool não se configuraram como processo desenvolvido anteriormente à chegada ao serviço de saúde. Algumas pessoas, apesar de não considerarem que o uso de álcool pudesse trazer algum problema para sua vida, aceitaram ir ao CAPSad apenas para atender a um pedido de um familiar ou de colegas de trabalho.

Uma característica do cuidado, oferecida e considerada importante, é a proposta de atendimento que prescinde da internação. Os usuários valorizam a ideia de serem atendidos no território e "aprendendo a conviver" com o álcool. Essa possibilidade de manterem os vínculos no território e o convívio familiar, também é vista como positiva, na medida em que possibilita a reconstrução de laços e a recuperação da "confiança" das pessoas que os cercam:

"Eu acho legal essa coisa de ir embora todo dia porque você fica mais fortalecido. Porque, vamos supor, o cara fica internado, bota o cara na rua, e ele vai procurar o bar. [...] E os familiares da gente vão vendo: 'Olha ele tá saindo, indo e voltando todo dia, e não tô sentindo um cheiro de bebida na boca dele'. Nessas daí, você vai ganhando ponto: 'Oh, ele tá indo e tá levando a sério'". (G)

Sobre o processo vivenciado após a entrada no serviço, são identificados resultados positivos em vários aspectos. Dentre estes, são mencionadas transformações significativas no próprio corpo. Além dos ganhos para a saúde, relatam que voltam a dar atenção às ações direcionadas ao autocuidado e aumento da "autoestima", que possibilitam novas formas de se estabelecerem nos relacionamentos interpessoais.

"A aparência influencia muito. Você chega com aquela cara inchada, parecendo o Kiko, magro, com hálito de bebida, quem vai te dar um emprego? [...] Ou você chega em qualquer ambiente e 'oh o cachaceiro, olha o bêbado aí chegando, nem vamos dar atenção pra esse cara...'. Agora, você chega e conversa de igual pra igual com todo mundo". (G)

Durante o processo de tratamento e reabilitação, os usuários constroem projetos de vida, de reorganização do cotidiano e de criação de outros espaços de pertencimento. Associam o uso de álcool ao abandono de muitas atividades e deveres e, ao falarem da elaboração desses projetos, associam este processo à ideia de "recuperar o tempo perdido":

"Eu faço [o meu dia a dia] ficar corrido. Porque eu acho que perdi muito tempo quando eu bebia, que não fazia nada. 'Ah, deixa que amanhã eu faço'. [...] Agora tô tentando colocar tudo em ordem". (F)

Mesmo após terem atingido a meta da abstinência, consideram importante a continuidade do acompanhamento no serviço, devido à característica de cronicidade dada ao alcoolismo: uma vez que não tem "cura", requer a manutenção constante dos cuidados. Assim, o acompanhamento permanente e de longa duração, no território, possibilita a continuidade da atenção, a prevenção de recaídas e a reconstrução de diversos aspectos da vida cotidiana.

“Existe ex-mulher, ex-marido. Agora, ex-alcoólatra não existe. [...] O cara é alcoólatra, é alcoólatra para vida inteira. Porque, qualquer coisinha, o cara recai". (F)

O CAPSad é visto como tendo uma função protetiva, que assegura a continência necessária para a continuidade dos cuidados que acreditam que precisam. Dessa forma, os depoentes continuaram frequentando o serviço por determinados períodos, mesmo após a interrupção do consumo de álcool.

$\mathrm{Na}$ avaliação dos sujeitos sobre as práticas de cuidado desenvolvidas no contexto do serviço, consideram importante o fato de o tratamento ser constituído por uma série de intervenções diferenciadas e articuladas: "Não é só tomando remédio que vai parar. A conversa, o dia a dia daqui que ajuda bem... (C)". Mas, de forma geral, os nomes dos profissionais com quem estabeleceram vínculo 
foram mais mencionados do que os grupos, atividades, ou qualquer outro procedimento em si, o que pode ser um indicativo da importância dada às relações estabelecidas no contexto do serviço.

O CAPSad torna-se um espaço importante de encontro e intercâmbio e, para alguns, o único lugar que frequentam e onde podem estabelecer trocas em seu cotidiano além da própria casa. $O$ vínculo com o serviço, com os funcionários e com os demais usuários apareceu de forma recorrente nas entrevistas e nos grupos focais. Houve um consenso sobre o que consideram o aspecto mais importante do cuidado oferecido pelo serviço: a possibilidade de encontro com as pessoas, sejam os profissionais ou os usuários.

"O melhor daqui são as pessoas. Todos. Desde o pessoal da faxina, as cozinheiras, os enfermeiros... Todos. Porque todos te tratam bem aqui. Você é tratado como um ser humano aqui. É isso que levanta a autoestima de todos aqui". (G)

\section{Considerações finais}

O consumo de bebidas alcoólicas é tolerado nas sociedades ocidentais e incentivado em campanhas publicitárias que as vinculam à imagem de figuras públicas e/ou as associam à juventude, à beleza, e ao sucesso (Acselrad, 2005; Carneiro, 2002).

É a substância mais utilizada em momentos de festas e comemorações, sendo, geralmente, nessas situações, junto com familiares e amigos, que os sujeitos experimentam bebidas alcoólicas pela primeira vez (Dias, 2008).

Nesse sentido, pode-se afirmar que o uso do álcool é orientado por regras sociais e de acordo com tradições culturais. Se, por um lado, é estimulado, por outro, a embriaguez excessiva e sem ponderação não é tolerada. Particularmente no Brasil, a mensagem socioculturalmente construída e amplamente veiculada é aprecie com moderação (Dias, 2008).

O conhecimento sobre esse problema mostra que a tensão entre o que seria o uso controlado, no contexto de determinado grupo social, representa uma questão em torno da qual os sujeitos constroem aspectos da experiência que envolve a identificação e busca de ajuda diante das consequências do uso prejudicial de álcool.

Como consequência da dificuldade de estabelecer o controle sobre o uso, entre outras, percebe-se que os sujeitos perdem contratualidade nos processos de trocas sociais. Nos relatos, identificamos que, frequentemente, suas opiniões não são consideradas, e sua força de trabalho é desqualificada nas relações cotidianas. São rotulados como bêbados, e suas identidades invalidadas e reduzidas à substância que consomem (Fiore, 2004).

Estamos diante de um campo problemático, no qual convivem muitas formas de se conceber a experiência da dependência e as estratégias de enfrentamento das questões associadas. Usuários, profissionais e familiares estão continuamente negociando significados e concepções acerca dos processos vivenciados e das formulações de tratamento e cuidado. Por meio da construção dos itinerários terapêuticos, foi possível conhecer a forma como os usuários compreendem suas experiências e os elementos que influenciam suas escolhas na busca de cuidado para suas aflições e que adquirem importância no percurso do tratamento.

Assim, os itinerários terapêuticos podem ser considerados recursos importantes para compor a construção de projetos terapêuticos cuidadores, centrados nas reais necessidades dos sujeitos, e que considerem e legitimem o conjunto de recursos, experiências e projetos de vida de cada pessoa.

Compreendemos, dessa forma, que a preocupação em conhecer os saberes e práticas dos sujeitos envolvidos na construção de seus itinerários terapêuticos deve compor as práticas de cuidado comprometidas com o fortalecimento dos sujeitos individuais e coletivos, com a construção de direitos e cidadania e com a produção de saúde e de vida. 
ITINERÁRIOS TERAPÊUTICOS ...

\section{Colaboradores}

As autoras trabalharam juntas em todas as etapas de produção do manuscrito.

\section{Referências}

ACSELRAD, G. A educação para a autonomia: construindo um discurso democrático sobre as drogas. In: . (Org.). Avessos do prazer: drogas, aids e direitos humanos. 2.ed. Rio de Janeiro: Fiocruz, 2005. p.183-212.

ALVES, P.C.B. A fenomenologia e as abordagens sistêmicas nos estudos sócio-antropológicos da doença: breve revisão crítica. Cad. Saude Publica, v.22, n.8, p.1547-54, 2006.

. A experiência da enfermidade: considerações teóricas. Cad. Saude Publica, v.9,

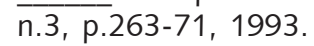

ALVES, P.C.B.; SOUZA, I.M.A. Escolha e avaliação de tratamento para problemas de saúde: considerações sobre o itinerário terapêutico. In: RABELO, M.C.M.; ALVES, P.C.B.; SOUZA, I.M.A. (Orgs.). Experiência de doença e narrativa. Rio de Janeiro: Fiocruz, 1999. p.125-38.

ANGROSINO, M. Etnografia e observação participante. Porto Alegre: Artmed, 2009.

ANTHONY, J.C. Consumo nocivo de álcool: dados epidemiológicos mundiais. In: ANDRADE, A.G.; ANTHONY, J.C. (Eds.). Álcool e suas consequências: uma abordagem multiconceitual. Barueri: Manole, 2009. p.1-36.

BRASIL. Ministério da Saúde. Secretaria de Atenção à Saúde/DAPE. Saúde mental no SUS: acesso ao tratamento e mudança do modelo de atenção. Relatório de Gestão 2003-2006. Brasília: MS, 2007.

. Ministério da Saúde. Portaria n.2197, 04 de outubro de 2004. Redefine e amplia a atenção integral para usuários de álcool e outras drogas, no âmbito do Sistema Único de Saúde - SUS, e dá outras providências. Diário Oficial da União, Brasília, DF, 15 out., 2004a. Seção 1, p.49-50.

Ministério da Saúde. Saúde Mental no SUS: os Centros de Atenção Psicossocial. Brasília: MS, 2004b. (Série F, Comunicação e Educação em Saúde).

. Ministério da Saúde. A política do Ministério da Saúde para a atenção integral a usuários de álcool e outras drogas. Brasília: MS, 2003. (Série B, Textos Básicos de Saúde).

Ministério da Saúde. Legislação em Saúde Mental, 1990-2002. 4.ed. Brasília: $\overline{M S}$, 2002. (Série E, Legislação de Saúde).

CARNEIRO, H. A fabricação do vício. In: ENCONTRO REGIONAL DE HISTÓRIA, 13., 2002, Mariana. Anais Eletrônicos... Mariana, 2002. p.9-24. Disponível em: <http:// www.neip.info>. Acesso: 15 jun. 2008.

COULON, A. Etnometodologia. Petrópolis: Vozes, 1995.

DENZIN, N.K.; LINCOLN, Y.S. (Eds.). O planejamento da pesquisa qualitativa: teorias e abordagens. Porto Alegre: Artmed, 2006.

DIAS, L.F. Usos e abusos de bebidas alcoólicas segundo os povos indígenas do Uaçá. In: LABATE, B.C. et al. (Orgs.). Drogas e cultura: novas perspectivas. Salvador: EDUFBA, 2008. p.199-217.

FIORE, M. Tensões entre o biológico e o social nas controvérsias médicas sobre uso de "drogas". In: REUNIÃO ANUAL DA ANPOCS, 28., 2004, Caxambu. Anais... Caxambu: 2004. Disponível em: <http://www.neip.info>. Acesso em: 15 jun. 2008. 
FRANCO, T.B.; MAGALHÃES JR., H.M. Integralidade na assistência à saúde: a organização das linhas do cuidado. In: MERHY, E.E. et al. (Orgs.). O trabalho em saúde: olhando o SUS no cotidiano. 3.ed. São Paulo: Hucitec, 2006. p.125-33.

FUNDAÇÃO SISTEMA ESTADUAL DE ANÁLISE DE DADOS - SEADE. Índice paulista de vulnerabilidade social. Disponível em: <http://www.seade.gov.br/produtos/ipvs/>. Acesso em: 20 jun. 2009.

GERHARDT, T.E. Itinerários terapêuticos em situações de pobreza: diversidade e pluralidade. Cad. Saude Publica, v.22, n.11, p.2449-63, 2006.

GIBBS, G. Análise de dados qualitativos. Porto Alegre: Artmed, 2009.

INSTITUTO BRASILEIRO DE GEOGRAFIA E ESTATÍSTICA - IBGE. Estimativas das populações residentes, em $1^{\circ}$ de julho de 2008, segundo os municípios. 2008. Disponível em: <http://www.ibge.gov.br>. Acesso em: 20 jun. 2009.

LARANJEIRA, R. et al. I levantamento nacional sobre padrões do consumo de álcool na população brasileira. Brasília: Secretaria Nacional Antidrogas, 2007.

MARQUES, A.L.M. Itinerários terapêuticos de sujeitos com problemáticas decorrentes do uso de álcool em um centro de atenção psicossocial. 2010. Dissertação (Mestrado) - Programa de Pós-Graduação em Ciências da Reabilitação, Faculdade de Medicina, Universidade de São Paulo. 2010.

MINAYO, MCS. O desafio do conhecimento: pesquisa qualitativa em saúde. São Paulo: Hucitec, 1993.

ORGANIZAÇÃO MUNDIAL DA SAÚDE- OMS. ORGANIZAÇÃO PAN-AMERICANA DA SAÚDE - OPAS. Relatório sobre a saúde no mundo - 2001. Saúde Mental: nova concepção, nova esperança. Genebra: OMS, 2001.

PROGRAMA DAS NAÇÕES UNIDAS PARA O DESENVOLVIMENTO - PNUD. Atlas do desenvolvimento humano no Brasil. 2003. Disponível em: <http://www.pnud.org.br/ atlas/>. Acesso em: 20 jun. 2009.

SANTANA DE PARNAÍBA. Secretaria Municipal de Planejamento. Plano Diretor do município de Santana de Parnaíba 2005-2006. 2006. Disponível em: <http:// www.santanadeparnaiba.sp.gov.br/plano_diretor.htm>. Acesso em: 20 jun. 2009.

SARACENO, B. La cittadinanza come forma di tolleranza. Rio de Janeiro, 1998. [Conferência]. Disponível em: <http://www.exclusion.net>. Acesso em: 13 set. 2008.

SILVERMANN, D. Interpretação de dados qualitativos: métodos para análise de entrevistas, textos e interações. Porto Alegre: Artmed, 2009.

WORLD HEALTH ORGANIZATION - WHO. Disease control priorities related to mental, neurological, developmental and substance abuse disorders: mental health evidence and research. Geneva: Department of Mental Health and Substance Abuse, 2004.

The World Health Report 2002: reducing risks, promoting healthy life. Geneva: WHO, 2002 
ITINERÁRIOS TERAPÊUTICOS $\ldots$

MARQUES, A.L.M.; MÂNGIA, E.F. Itinerarios terapéuticos de las personas con problemas derivados del uso perjudicial del alcohol. Interface (Botucatu), v.17, n.45, p.433-44, abr./jun. 2013.

Este estudio tuvo como objetivo conocer los itinerarios terapéuticos de sujetos con problemas derivados del uso perjudicial del alcohol en un Centro de Atención Psicosocial para usuarios de alcohol y otras drogas - CAPSad. La investigación, de carácter cualitativo, adoptó la perspectiva etno-metodológica y empleó los procedimientos metodológicos de revisión de literatura, investigación documental, entrevistas semi-estructuradas, grupo focal, observación participante y diario de campo. Los itinerarios terapéuticos se configuran con base en la experiencia acumulada que dota de significados las experiencias relacionadas al uso del alcohol y la necesidad de ayuda. Se destaca la importancia de las redes sociales y de relaciones, en el contexto de las cuales se comparten sentidos, significados y apoyo. El curso del estudio demostró la importancia de conocer los conocimientos y prácticas de los sujetos en la propuesta de las prácticas de atención comprometidas con la producción de la salud y de la vida.

Palabras clave: Itinerarios terapéuticos. Trastornos relacionados con sustancias. Alcoholismo. Servicios comunitarios de salud mental.

Recebido em 01/06/12. Aprovado em 30/04/13. 